\title{
COMPARISION OF THE EFFICACY AND SAFETY PROFILE OF SITAGLIPTIN AND GLIMIPIRIDE IN TYPE 2 DIABETIC PATIENTS.
}

1. MBBS, M.Phil (Pharmacology) Associate Professor Pharmacology Sheikh Zayed Medical College, Rahim Yar Khan.

2. MBBS, M.Phil (Pharmacology) Assistant Professor Pharmacology Islam Medical, Sialkot.

3. MBBS, M.Phil (Pharmacology) Associate Professor Pharmacology HBS Medical \& Dental College, Islamabad.

4. MBBS, FCPS (Medicine) Senior Registrar Medicine Sheikh Zayed Hospital, Rahim Yar Khan.

5. MBBS, M.Phil (Hematology) Associate Professor Hematology Sheikh Zayed Medical College, Rahim Yar Khan.

6. MBBS, FCPS (Gynae \& Obs) Senior Demonstrator Pharmacology Sheikh Zayed Medical College, Rahim Yar Khan.

Correspondence Address:

Dr. Mazhar Hussain

House No 214/C Satellite Town,

Rahim Yar Khan.

mazharhussain214@gmail.com

Article received on:

$11 / 03 / 2019$

Accepted for publication:

10/10/2019
Mazhar Hussain ${ }^{1}$, Muhammad Amir Rafique ${ }^{2}$, Abdul Qudoos Arain ${ }^{3}$, Shoaib Akhtar ${ }^{4}$, Muhammad Bilal Ghafoor ${ }^{5}$, Lubna Akhtar ${ }^{6}$

ABSTRACT... Objectives: To compare the efficacy and safety profile of sitagliptin vs. glimepiride in type 2 diabetic patients. Study Design: Comparative study. Setting: Medical Unit, Islam Centarl Hospital Sialkot. Period: September to December 2018. Material \& Methods: In which Type 2 diabetic patients $(n=220)$ were randomly placed into interventional groups to prescribed either sitagliptin or glimepiride for an interval of 16 weeks. A blood sugar level was maintained by dose titration in both groups. The main end point was change in FBG \& HbA1C while additional end point was change in body weight, hypoglycemic episodes and gastrointestinal adverse effects from baseline by using SPPS 16. Results: After 16 weeks of treatment both sitagliptin and glimepiride caused a significant improvement $(\mathrm{P}<0.001)$ in glycemic control by reducing FBG $(-22 \pm 3.2 \&-33.5 \pm 4.4) \& \mathrm{HbA} 1 \mathrm{C}(0.78 \pm 0.3 \& 1.12 \pm 0.25)$ respectively. However when comparison was done between two group, glimepiride has more pronounced effect on glycemic control as compared to sitagliptin $(P<0.001)$. Net $B M I$ reduced to $0.8 \pm 0.68$ in sitagliptin group while net $\mathrm{BMI}$ increased to $1.1 \pm 0.78$ in glimepiride treated group with $(\mathrm{P}<0.001)$. There were no adverse effects reported in sitagliptin treated group while 25 hypoglycemic episodes were noticed in glimepiride treated group. Conclusion: Glimepiride has more pronounced effect on glycemic control as compared to sitagliptin. However this pronounced effect was associated with more hypoglycemic episodes and weight gain. Euglycemic effect and weight reducing property of sitagliptin precludes that it has better safety and tolerability profile in comparison with glimepiride.

Key words: $\quad$ Body Weight, BMI, Glimepiride, HbA1c, Sitagliptin.

Article Citation: Hussain M, Rafique MA, Arain MQ, Akhtar S, Ghafoor MB, Akhtar L. To compare the efficacy and safety profile of sitagliptin and glimipiride in type 2 diabetic patients. Professional Med J 2020; 27(5):895-901.

DOI: 10.29309/TPMJ/2020.27.05.3401

\section{INTRODUCTION}

Type 2 diabetes mellitus is rising at an alarming rate all across globe. Out of every 11 adults, 1 has diabetes mellitus now. The number of diabetic patients and its associated complications increases day by day more in Asians countries because of strong genetic predisposition. Moreover developing countries far behind in controlling diabetes related risk factors such as obesity, dyslipidemia, physical inactivity, sedentary life style, urbanization and stress. ${ }^{1}$ Therefore a self management education and support is required in order to prevent and control diabetes associated risk factors and complications. This will reduce social and economic burden of diabetes on public health system. $^{2}$
Life style modifications usually consider first in the managementoftype2diabetes. Oral hypoglycemic agents and insulin are other options if glycemic control can be achieve within therapeutic range in spite of life style modification Antidiabetic drugs act through various mechanisms to counter act the increase level of glucose in diabetic patients. They inhibit glucose absorption from intestine, decease glucose production from liver, increase insulin release from pancreas, inhibits glucose reabsorption from proximal tubules and increases insulin sensitivity. ${ }^{2-3}$

Sitagliptin is an oral antidiabetic agent that use as monotherapy or combination therapy in diabetes patients. It increases the physiological concentration of two gastrointestinal hormones 
glucagon like peptide (GLP) and gastric inhibitory peptide (GIP) in body. It increases these enzyme concentrations by inhibiting another enzyme called dipeptidyl peptidase 4 (DPP-4) Sitagliptin control blood sugar through various actions such as suppression of appetite, increase insulin release from pancreas, inhibits glucagon production and increases insulin sensitivity towards peripheral tissues. Sitagliptin has an excellent glycemic control profile with no risk of hypoglycemia. Moreover sitagliptin has a mild decrease or neutral effect on body weight. ${ }^{4-5}$ Moreover sitagliptin has many useful effects on other body system such as blood pressure, inflammation, lipid profile, oxidative stress, endothelial and myocardial dysfunction. ${ }^{6}$

Glimepiride is one of the $2^{\text {nd }}$ generation sulfonylurea groups of oral antidiabetic drug. Glimepiride is prescribed mostly in type 2 diabetic patients either alone or in combination therapy. It acts as an insulin secretagogue and increases insulin production from the beta cells of pancreas. Glimepiride has also good glycemic control profile in most of the type 2 diabetic patients. However in comparison with first generation sulfonylurea, glimepiride is associated with low risk of hypoglycemia. Moreover it is associated with increase in body weight in most of the type 2 diabetic patients. ${ }^{7}$

The present study was conducted to compare the effects of sitagliptin and glimepiride in terms of $\mathrm{HbA1C}$, body weight, hypoglycemic episodes and gastrointestinal adverse effects over a period of 16 weeks.

\section{MATERIAL \& METHODS}

This 16 weeks comparative clinical trial was conducted at Islam Central Hospital at its medical outdoor from September to December 2018. An ethical permission and informed consent was taken before start of study. In the beginning, 350 patients of type 2 diabetes were screened at medical outdoor over a period of 6 months. From which 220 were recruited for the study in terms of inclusion and exclusion criteria. The inclusion criterion was type 2 diabetic patients aged 42-65 with HbAlc 7.5-9\% and BMI 27-29.
The exclusion criteria include detailed history, clinical examination and routine test to rule out any diabetes related complication in the form of neuropathy, nephropathy and retinopathy. In addition patients with history of type 1 diabetes, smoking, alcohol, hypertension, cardiac diseases, renal and hepatic disorders were excluded from the study. In addition those patients whose glycemic level should not be controlled within 4 weeks of study were excluded from the study.

These patients were randomly divided in a ratio of 1:1 in two groups. These patients had inadequate glycemic control and were switched from metformin routine to sitagliptin and glimepiride over a washout period of 2 weeks. Patients in Group A were given tablet sitagliptin $50 \mathrm{mg}$ while patients in group B were given tablet glimepiride $1 \mathrm{mg}$ initially. The doses of both drugs were adjusted according to their blood sugar level. Most of the patients were adjusted on sitagliptin $100 \mathrm{mg}$ and glimepiride $2 \mathrm{mg}$ daily after 04 weeks of treatment. Treatment was continued over a period of 16 weeks. A digital weight machine was used to measure body weight. A microtoise was used to measure height. Measurements were done by wearing light clothes and without shoes. A standard formula, weight in $\mathrm{kg}$ divided by height in meter square $\left(\mathrm{kg} / \mathrm{m}^{2}\right)$ was used to calculate BMl. A $5 \mathrm{ml}$ overnight fasting blood sample was taken from cephalic vein through aseptic technique. After clotting and centrifugation, serum was separated and stored at $4{ }^{\circ} \mathrm{C}$ for 1 hour until analyzed for $\mathrm{HbA} 1 \mathrm{C}$ and serum lipid profile. A glucose oxidase peroxidase method was used to estimate blood sugar while liquid chromatography and enzymatic end point method was used to determined $\mathrm{HbA} 1 \mathrm{c}$ and serum lipid profile respectively.

Statistical package for social sciences (SPSS-16) was used to analyze data. Parametric data such as body weight, BMI, blood sugar and HbAlc were expressed as mean \pm SD from baseline. The adverse effects and hypoglycemic episodes were expressed as numbers. The comparison among group and between groups was done by paired $t$ test and student $t$-test. $P$ value $<0.01$ were seemed to be statistically significant. 


\begin{tabular}{|c|c|c|c|}
\hline Demographic Characteristics & $\begin{array}{c}\text { Sitagliptin } \\
(\mathrm{N}=110)\end{array}$ & $\begin{array}{c}\text { Glimepiride } \\
(\mathrm{N}=110)\end{array}$ & P-Value \\
\hline Age (years) & $54.6 \pm 8.8$ & $48.5 \pm 12.5$ & 0.76 \\
\hline Gender(M/F) & $71(64.5 \%) / 39(35.4 \%)$ & $64(58.1 \% / 46(41.9 \%)$ & 0.32 \\
\hline Body weight (kg) & $79 \pm 12.5$ & $82 \pm 14.6$ & 0.88 \\
\hline $\mathrm{BMI}(\mathrm{kg} / \mathrm{m} 2)$ & $28 \pm 5.3$ & $27 \pm 3.8$ & 0.12 \\
\hline Diabetes duration (years) & $5.6 \pm 4.2$ & $5.2 \pm 6.5$ & 0.98 \\
\hline \multicolumn{4}{|l|}{ Parameters Lab (mean \pm SD) } \\
\hline Serum glucose $F(\mathrm{mg} / \mathrm{dl})$ & $160 \pm 12.5$ & $155 \pm 14.2$ & 0.62 \\
\hline $\mathrm{HbA1c}(\%)$ & $8.4 \pm 0.9$ & $8.2 \pm 0.82$ & 0.42 \\
\hline Total Cholesterol(mg/dl) & $186 \pm 34.56$ & $170.5 \pm 30.5$ & 0.77 \\
\hline Triglycerides(mg/dl) & $157 \pm 20.76$ & $166 \pm 24.8$ & 0.23 \\
\hline LDL-Cholesterol(mg/dl) & $110 \pm 14.6$ & $118 \pm 18.3$ & 0.43 \\
\hline HDL-Cholesterol(mg/dl) & $43.5 \pm 4.62$ & $44 \pm 4.26$ & 0.82 \\
\hline
\end{tabular}

\begin{tabular}{|l|c|c|c|c|c|c|c|}
\hline \multicolumn{3}{|c}{ Group A Sitagliptin(n=110) } & \multicolumn{3}{c|}{ Group B glimepiride (n=110) } \\
\hline Parameters & 0 weeks & $\mathbf{1 6}$ weeks & $\begin{array}{c}\text { Mean } \\
\text { Difference }\end{array}$ & Parameters & 0 weeks & $\mathbf{1 6}$ weeks & Mean Difference \\
\hline BMI $(\mathrm{kg} / \mathrm{m} 2)$ & $28 \pm 5.3$ & $26.5 \pm 4.2$ & $-0.8 \pm 0.68$ & BMl $(\mathrm{kg} / \mathrm{m} 2)$ & $27 \pm 3.8$ & $27.9 \pm 3.2$ & $+1.1 \pm 0.78$ \\
\hline FBG $(\mathrm{mg} / \mathrm{dl})$ & $154 \pm 10.2$ & $134 \pm 12.5$ & $-22 \pm 3.2$ & FBG $(\mathrm{mg} / \mathrm{dl})$ & $160.5 \pm 13.4$ & $130 \pm 10.8$ & $-33.5 \pm 4.4$ \\
\hline HbA1c $(\%)$ & $8.4 \pm 0.9$ & $7.62 \pm 0.62$ & $-0.78 \pm 0.3$ & HbA1c $(\%)$ & $8.2 \pm 0.82$ & $7.4 \pm 0.55$ & $-1.12 \pm 0.25$ \\
\hline
\end{tabular}

\section{RESULTS}

The compliance of both drugs was quite good and no patient was dropped out from the study. Demographic parameters (Table-l) at start of study showed no significant statistical difference in both study groups. There was significant improvement $(P<0.001)$ in glycemic control after 16 weeks treatment in both sitagliptin and glimepiride treated groups. HbA1c value was decreased from $8.4 \pm 0.9$ to $7.62 \pm 0.62$ with a net reduction of $-0.78 \pm 0.3 \%$ in sitagliptin treated group. While in glimepiride treated group $\mathrm{HbA1C}$ value was also decreased from $8.2 \pm 0.82$ to $7.4 \pm 0.55$ with a net reduction of $1.12 \pm 0.25 \%$. Both groups showed a significant reduction $(P<0.001)$ in fasting blood sugar level. The mean fasting blood sugar level was reduced by $22 \pm 3.2$ in sitagliptin and $33.5 \pm 4.4$ in glimepiride treated group respectively. However comparison between two group revealed that glimepiride was statistically significant effect on glycemic control in comparison with sitagliptin $(P<0.001)$. The net reduction of $\mathrm{BMI}$ was $0.8 \pm 0.68$ in sitagliptin treated group while $\mathrm{BMI}$ increased to $1.1 \pm 0.78$ in glimepiride treated group with $(P<0.001)$. The safety and tolerability profile of sitagliptin and glimepiride was quite good with no major adverse effects were noted during the study. However 4 patients in sitagliptin group and 5 patients in the glimepiride group were complaint of abdominal distention at start of study which was settle down itself without any treatment. There was no single episode of hypoglycemia reported in sitagliptin group. On the other hand we have noticed 25 hypoglycemic episodes in the form of lightheadness, sweating, anxiety and confusion in glimepiride treated group.

\section{DISCUSSION}

In this comparative study sitagliptin and glimepiride were assessed in terms of body weight, glycemic control, hypoglycemic episodes and gastrointestinal adverse effects over a period of 16 weeks. In our study both drugs improved glycemic control marked by significant reduction of FBG and $\mathrm{HbA1c}$. This improvement in glycemic control was further accompanied by reduction in body weight with no hypoglycemic episode 
in sitagliptin treated group while glimepiride treated group was associated with increase in body weight and increase risk of hypoglycemic episodes. However no gastrointestinal and other adverse effects were noted in both study groups.

The results of our study were in consistent with various studies in which sitagliptin improved glycemic control and reduced body weight with no risk of hypoglycemia. Sitagliptin reduced BMI $0.8 \pm 0.68(\mathrm{~kg} / \mathrm{m})$ and $\mathrm{HbA1C} 0.78 \pm 0.3 \%$ in our study which were almost similar to study conducted by Yanai et $\mathrm{el}^{8}$ which revealed that sitagliptin treatment significantly reduced body weight and $\mathrm{HbA1c}$ in type 2 diabetes over a period of 6 months. Sitagliptin reduced $\mathrm{HbA1C}$ 0.43 to $1.0 \%$ and body weight 0.2 to $2 \mathrm{~kg}$ in various clinical studies. ${ }^{9-12}$ However duration of these studies were 6 months or more. Aschner et $\mathrm{al}^{9}$ also observed that sitagliptin has more pronounced effect on HbAlc $>8 \%$ as compared to HbA1c $7.2 \%$. These studies also shown that sitagliptin either monotherapy or as combination therapy with metformin significantly reduced body weight. Moreover combination with metformin as additive effect on reducing body weight as metformin has well known for its weight reducing property.

However two studies also showed that sitagliptin increased body weight +0.4 and $+0.28 \mathrm{~kg}$. This increase in body weight was mainly caused by as add on therapy with pioglitazone and glimepiride. The increase in body weight by both of these drugs is already well understood. ${ }^{13-14}$ However a study conducted by Nonaka et $\mathrm{al}^{15}$ revealed that sitagliptin reduced $\mathrm{HbA} 1 \mathrm{C} \quad 0.65 \%$ without any hypoglycemic episodes but had no effect on body weight in contrast to our study.

A tight glycemic control was achieved by glimepiride in our study as compared to sitagliptin. This tight glycemic control was associated with more hypoglycemic attacks in glimepiride versus sitagliptin group. Similar results were observed in other studies revealing that glimepiride although has an excellent glycemic control profile but associated with more hypoglycemic episodes in comparison with sitagliptin. Further there was increase in body weight by glimepiride which was similar to various studies that concluded that average weight gain by glimepiride was +1 to $2 \mathrm{~kg}$ in type 2 diabetic patients over a period of 12 weeks to 2 years. ${ }^{16-18}$

There were limited studies about comparison between sitagliptin and glimepiride in terms of glycemic control, body weight and tolerability profile. Similar to our study Srivastava et al ${ }^{19}$ revealed that although glimepiride had more beneficial effect on glycemic control but it was also associated with more hypoglycemic attacks and weight gain as compared to sitagliptin. Two another studies ${ }^{20-21}$ pointed out that DPP-4 inhibitors, sitagliptin and saxagliptin showed a better tolerability and safety profile as compared to glimepiride in elderly type 2 diabetic patients with inadequate glycemic control. However multicentre randomized control trial conducted by ferrannini et $\mathrm{a}^{22}$ demonstrated that DPP4 inhibitor displayed a comparable efficacy but more safety profile in comparison with glimepiride over a period of 52 weeks in type 2 diabetic patients. Similarly meta analysis of 10 randomized control trial showed that there were no difference between sitagliptin and glimepiride in terms of clinical efficacy when added to patients who were inadequately controlled with metformin monotherapy. Body weight decreased by $2.2 \mathrm{~kg}$ and only one hypoglycemic episode were recorded over a follow up in 10,616 patients of type 2 diabetes. ${ }^{23}$ While a systematic review and meta analysis of 16 randomized trial showed that both drugs can be used as an add on therapy in type 2 diabetic patients whose blood sugar was inadequately controlled with metformin. However glimepiride was associated increase risk of hypoglycemia and weight gain in comparison with sitagliptin which was associated with no risk of hypoglycemia and weight loss. ${ }^{24}$ Another meta analysis of 41 randomized controlled trial concluded that sitagliptin has excellent safety profile with a mean reduction of $\mathrm{HbA} 1 \mathrm{c} 0.6$ to $0.8 \%$ lesser than sulphonylureas but without gaining weight and low risk of hypoglycemia similar to our study. ${ }^{25}$ (monami). A systematic review and meta analysis of 19 studies yield similar result in sense that DPP-4 inhibitors lower HbA1C in 
same way as sulphonuluras or pioglitazonre with neutral effect on body weight and without hypoglycemia. ${ }^{26}$ (Karagiannis).

Moreover DPP-4 inhibitors have additional benefits as compared to glimepiride on risk factors in type 2 diabetic patients. They reduce blood pressure, inflammatory markers, apoptosis and oxidative stress. They also improve lipid profile, postprandial lipaemia, endothelial and myocardial dysfunction. Seeing these pleiotropic effects, sitagliptin has strong potential against ischemic, atherosclerotic and hypertensive cardiovascular diseases. ${ }^{27-29}$

\section{CONCLUSION}

Glimepiride has more pronounced effect on glycemic control as compared to sitagliptin. However this pronounced effect was associated with more hypoglycemic episodes and weight gain. Euglycemic effect and weight reducing property of sitagliptin precludes that it has better safety and tolerability profile in comparison with glimepiride.

\section{Copyright $(10$ Oct, 2019.}

\section{REFERENCES}

1. Zheng $\mathrm{Y}$, Ley $\mathrm{SH}$, Hu FB. Global aetiology and epidemiology of type 2 diabetes mellitus and its complications. Nature Reviews Endocrinology. 2018 Feb; 14(2):88.

2. Reusch JE, Manson JE. Management of type 2 diabetes in 2017: Getting to goal. Jama. 2017 Mar 14; 317(10):1015-6.

3. Olokoba AB, Obateru OA, Olokoba LB. Type 2 diabetes mellitus: A review of current trends. Oman medical journal. 2012 Jul; 27(4):269.

4. Omar B, Ahrén B. Pleiotropic mechanisms for the glucose-lowering action of DPP-4 inhibitors. Diabetes. 2014 Jul 1; 63(7):2196-202.

5. Mulvihill EE, Drucker DJ. Pharmacology, physiology, and mechanisms of action of dipeptidyl peptidase-4 inhibitors. Endocrine reviews. 2014 Sep 12; 35(6):9921019.

6. Fadini GP, Avogaro A. Cardiovascular effects of DPP4 inhibition: beyond GLP-1. Vascular pharmacology. 2011 Jul 1; 55(1-3):10-6.
7. Sola D, Rossi L, Schianca GP, Maffioli P, Bigliocca M, Mella R, Corlianò F, Fra GP, Bartoli E, Derosa G. Sulfonylureas and their use in clinical practice. Archives of medical science: AMS. 2015 Aug 12; 11(4):840.

8. Yanai $\mathrm{H}$, Adachi $\mathrm{H}$, Hamasaki $\mathrm{H}$, Masui $\mathrm{Y}$, Yoshikawa R, Moriyama S, Mishima S, Sako A. Effects of 6-month sitagliptin treatment on glucose and lipid metabolism, blood pressure, body weight and renal function in type 2 diabetic patients: a chart-based analysis. Journal of clinical medicine research. 2012 Aug; 4(4):251.

9. Aschner P, Katzeff HL, Guo H, Sunga S, WilliamsHerman D, Kaufman KD, Goldstein BJ. Efficacy and safety of monotherapy of sitagliptin compared with metformin in patients with type 2 diabetes. Diabetes Obes Metab. 2010; 12(3):252-261.

10. Oz O, Kiyici S, Ersoy C, Cander S, Yorulmaz H, Gul $\mathrm{CB}$, Unal OK. et al. Effect of sitagliptin monotherapy on serum total ghrelin levels in people with type 2 diabetes. Diabetes Res Clin Pract. 2011; 94(2):212216.

11. Scott R, Loeys T, Davies MJ, Engel SS. Efficacy and safety of sitagliptin when added to ongoing metformin therapy in patients with type 2 diabetes. Diabetes Obes Metab. 2008; 10(10):959-969.

12. Derosa G, Maffioli P, Salvadeo SA, Ferrari I, Ragonesi PD, Querci F, Franzetti IG. et al. Effects of sitagliptin or metformin added to pioglitazone monotherapy in poorly controlled type 2 diabetes mellitus patients. Metabolism. 2010; 59(6):887-895.

13. Kashiwagi A, Kadowaki T, Nonaka K, Taniguchi T, Mishii M, Ferreira JCA. et al. Sitagliptin added to treatment with ongoing pioglitazone for us to 52 weeks improves glycemic control in Japanese patients with type 2 diabetes. J Diabetes Invest. 2011; 2(5):381-390.

14. Tajima NA, Kadowaki T, Odawara M, Nishii M, Taniguchi T, Ferreira JCA. Addition of sitagliptin to ongoing glimepiride therapy in Japanese patients with type 2 diabetes over 52 weeks leads to improved glycemic control. Diabetol Int. 2011; 2(2):32-34.

15. Nonaka K, Kakikawa T, Sato A, Okuyama K, Fujimoto G, Kato N, Suzuki H, Hirayama Y, Ahmed T, Davies MJ, Stein PP. Efficacy and safety of sitagliptin monotherapy in Japanese patients with type 2 diabetes. Diabetes research and clinical practice. 2008 Feb 1;79(2):2918. 
16. Phung OJ, Scholle JM, Talwar M, Coleman Cl. Effect of noninsulin antidiabetic drugs added to metformin therapy on glycemic control, weight gain, and hypoglycemia in type 2 diabetes. Jama. 2010 Apr 14; 303(14):1410-8.

17. Garber A, Henry RR, Ratner R, Hale P, Chang CT, Bode $B$. Liraglutide, a once $\square$ daily human glucagonlike peptide 1 analogue, provides sustained improvements in glycaemic control and weight for 2 years as monotherapy compared with glimepiride in patients with type 2 diabetes. Diabetes, obesity and metabolism. 2011 Apr; 13(4):348-56.

18. Hirst JA, Farmer AJ, Dyar A, Lung TW, Stevens RJ. Estimating the effect of sulfonylurea on HbA1c in diabetes: A systematic review and meta-analysis.

19. Srivastava S, Saxena GN, Keshwani P, Gupta R. Comparing the efficacy and safety profile of sitagliptin versus glimepiride in patients of type 2 diabetes mellitus inadequately controlled with metformin alone. J Assoc Physicians India. 2012 Mar; 60(2):27-30.

20. Schernthaner G, Durán-Garcia S, Hanefeld M, Langslet G, Niskanen L, Östgren CJ, Malvolti E, Hardy E. Efficacy and tolerability of saxagliptin compared with glimepiride in elderly patients with type 2 diabetes: A randomized, controlled study (GENERATION). Diabetes, Obesity and Metabolism. 2015 Jul; 17(7):6308.

21. Terauchi $Y$, Yamada $Y$, Ishida $H$, Ohsugi $M$, Kitaoka M, Satoh J, Yabe D, Shihara N, Seino Y. Efficacy and safety of sitagliptin as compared with glimepiride in Japanese patients with type 2 diabetes mellitus aged $\geq 60$ years (START-J trial). Diabetes, Obesity and Metabolism. 2017 Aug; 19(8):1188-92.

22. Ferrannini E, Fonseca V, Zinman B, Matthews D, Ahrén B, Byiers S, Shao Q, Dejager S. Fifty-two-week efficacy and safety of vildagliptin vs. glimepiride in patients with type 2 diabetes mellitus inadequately controlled on metformin monotherapy. Diabetes, Obesity and Metabolism. 2009 Feb; 11(2):157-66.
23. Foroutan N, Muratov S, Levine M. Safety and efficacy of dipeptidyl peptidase-4 inhibitors vs sulfonylurea in metformin-based combination therapy for type 2 diabetes mellitus: Systematic review and metaanalysis. Clinical \& Investigative Medicine. 2016 Apr 2; 39(2):48-62.)(_follow up of 10163 patients).

24. Mishriky BM, Cummings DM, Tanenberg RJ. The efficacy and safety of DPP4 inhibitors compared to sulfonylureas as add-on therapy to metformin in patients with type 2 diabetes: a systematic review and meta-analysis. Diabetes research and clinical practice. 2015 Aug 1; 109(2):378-88.

25. Monami M, lacomelli I, Marchionni N, Mannucci E. Dipeptydil peptidase-4 inhibitors in type 2 diabetes: A meta-analysis of randomized clinical trials. Nutrition, Metabolism and Cardiovascular Diseases. 2010 May 1; 20(4):224-35.

26. Karagiannis T, Paschos P, Paletas K, Matthews DR, Tsapas A. Dipeptidyl peptidase-4 inhibitors for treatment of type 2 diabetes mellitus in the clinical setting: Systematic review and meta-analysis. BMJ. 2012 Mar 12; 344:e1369.

27. Chin HJ, Nam JH, Lee EK, Shin JY. Comparative safety for cardiovascular outcomes of DPP-4 inhibitors versus glimepiride in patients with type 2 diabetes: A retrospective cohort study. Medicine. 2017 Jun; 96(25).

28. Scheen AJ. Cardiovascular effects of gliptins. Nature Reviews Cardiology. 2013 Feb; 10(2):73.

29. Zhou Y, Guo Z, Yan W, Wang W. Cardiovascular effects of sitagliptin-An anti-diabetes medicine. Clinical and Experimental Pharmacology and Physiology. 2018 Apr 21. 


\section{AUTHORSHIP AND CONTRIBUTION DECLARATION}

\begin{tabular}{|c|c|c|c|}
\hline Sr. \# & Author(s) Full Name & Contribution to the paper & Author(s) Signature \\
\hline 1 & Mazhar Hussain & $\begin{array}{l}\text { Conceived the idea, Search } \\
\text { literature \& wrote the paper. }\end{array}$ & \\
\hline 2 & M. Amir Rafique & $\begin{array}{l}\text { Designed the study and } \\
\text { Collected clinical data. }\end{array}$ & M.thmis enfive \\
\hline 3 & Abdul Qudoos Arain & $\begin{array}{l}\text { Preparing the manuscript, data } \\
\text { analysis and interpretation of } \\
\text { discussion. }\end{array}$ & \\
\hline 4 & Shoaib Akhtar & $\begin{array}{l}\text { Search the literature, } \\
\text { manuscript editing and drafting } \\
\text { of the manuscript. }\end{array}$ & \\
\hline 5 & M. Bilal Ghafoor & $\begin{array}{l}\text { Manuscript review, Proof } \\
\text { reading and laboratory data } \\
\text { analysis. }\end{array}$ & \\
\hline 6 & Lubna Akhtar & $\begin{array}{l}\text { Final editing, plagiarism and } \\
\text { assisted in final writing of } \\
\text { manuscript. }\end{array}$ & \\
\hline
\end{tabular}

